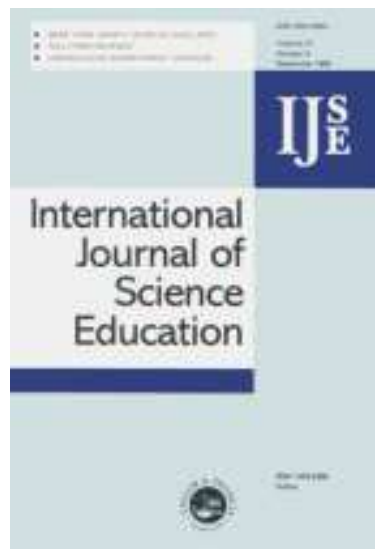

\title{
Promoting science outdoor activities for elementary school children: \\ Contributions from a research laboratory
}

\begin{tabular}{|r|l|}
\hline Journal: & International Journal of Science Education \\
\hline Manuscript ID: & TSED-2010-0098.R2 \\
\hline Manuscript Type: & Research Paper \\
\hline Keywords: & \\
\hline Keywords (user): & \\
\hline
\end{tabular}

\section{SCHOLARONEm \\ Manuscripts}

URL: http://mc.manuscriptcentral.com/tsed Email: editor_ijse@hotmail.co.uk 


\section{$1 \quad$ Abstract}

2 The purposes of the study were to analyse the promotion of scientific literacy through

3 practical research activities, and to identify children's conceptions about scientists and

4 how they do science. Elementary school children were engaged in two scientific

5 experiments in a marine biology research laboratory. A total of 136 students answered a

6 questionnaire about their previous habits towards science and carried out the following

7 actions: i) a guided visit to the laboratory; ii) a brief presentation of the research theme;

8 iii) the development of two experiments; iv) a questionnaire about the experiments and

9 science conceptions. The research methods included observation, document analysis

10 and content analysis of the answers to the questionnaires. Additionally, each visit was

11 video recorded in order to design learning materials. The results revealed that most of

12 the pupils were able to follow every stage of experimentation. However, some of them

13 misinterpreted results and conclusions. One implication of the study is that this type of

14 outdoor activity is extremely important to promote meaningful science learning in

15 children, but more care should be taken in practical science activities so that children

16 can overcome some common difficulties when performing scientific inquiry.

\section{Introduction}

19 A number of recent studies have enhanced students' awareness about scientific activity

20 and science processes as a central aim of science education (e.g. Hume \& Coll, 2008;

21 Mant, Wilson \& Coates, 2007).

23 To achieve this goal, some collaboration programs were developed between schools and

24 research laboratories, with the intention of providing students with opportunities to do

25 real science (e.g. Barab \& Hay, 2001; Richmond \& Kurth, 1999). Given the procedural 
1 nature of inquiry-based activities they are more likely to encourage relationships

2 between the stakeholders of both formal and informal education, like the research

3 laboratories, creating opportunities to involve both scientists and educators in science

4 education (Rocard et al., 2007). Moreover, this type of collaboration creates an

5 opportunity for students to engage in practical activities that are different from what is

6 possible to take place in a school setting.

7

8 Skills which relate to scientific procedures, such as posing a research problem,

9 formulating hypotheses, designing experiments, collecting and recording data, and

10 drawing conclusions, have been recognised as essential components of any science

11 curriculum (e.g. Atkin \& Black, 2003; Rocard et al., 2007). Nowadays, many science

12 curricula, namely the Portuguese one, require students to differentiate between theory

13 and evidence, to collect and record data, and to describe experimental observations and

14 results, as well as to draw conclusions (Galvão, 2001). In order to be effective these

15 skills must be developed at all school levels (Rocard et al., 2007).

17 There is, however, some debate about what students can learn with this kind of

18 scientific experimentation. The dependency of reasoning skills upon specific contexts

19 makes it impossible to predict how children will be able to perform on such occasions

20 (Zohar, 1998). One direction for research is to examine what students at different grade

21 levels can do in an experimental setting without a recipe to follow (Mayer \& Carlisle, 22 1996).

24 At an elementary school level, it is usually assumed that children are intrinsically 25 interested in science and curious about the scientific phenomena that surround them 

common difficulties.

17 The study had three specific aims: possible implications in their science understanding and conceptions.

\section{Theoretical background}


1 One of the major goals of science education is the development of scientific literate

2 citizens (Millar \& Osborne, 1998). Scientific literacy is commonly portrayed as the

3 ability to make informed decisions on science and technology-based issues and is

4 linked to deep understandings of scientific concepts, the processes of scientific inquiry,

5 and the nature of science (Bell, Blair, Crawford \& Lederman, 2003). Recent reforms in

6 science education stress the need of leading science curricula to a more authentic picture

7 of science (e.g. Anderson 2007; Duggan \& Gott, 2002; Ryder, 2001; Schreiner \&

8 Sjøberg, 2004; Singer, Hilton \& Scwiengruber, 2005). Consequently, scientific inquiry

9 that enables students to apply both substantive and procedural knowledge in order to

10 perform investigations in a way that mirrors actual practices of scientific communities,

11 has re-emerged as the emphasis of new curriculum approaches (Atkin \& Black, 2003;

12 Rocard et al., 2007). According to Hofstein and Lunetta (2003), through such an

13 authentic inquiry "learners can investigate the natural world, propose ideas, and explain

14 and justify assertions based upon evidence and, in the process, sense the spirit of

15 science." (p. 30).

16

17 However, while most of the science education community agrees with the fact that

18 pedagogical practices based on inquiry methods are more effective, numerous studies

19 have already shown that school practices do not follow this approach (e.g. Lederman,

20 1992; Matthews, 1994; Meichtry, 1992; Rocard et al., 2007). In fact, the practical work

21 usually developed in schools seems to bear little resemblance to inquiry as practiced by

22 scientists (e.g. Chin \& Kayalivizhi, 2002; Hipkins et al., 2001; Nakhlel, Polles \&

23 Malina, 2002). According to Mant et al. (2007), much of the students practical work,

24 even at secondary level, is focussed on recipe-style laboratory exercises and 'control of

25 variables' model of science investigation. This type of practical work involves closed 
It is generally believed that the more authentic a research experience is, such as an

16 apprenticeship guided by a science professional, the more likely students will learn

17 about aspects of scientific inquiry. Science educators have assumed that working on

18 authentic science research projects facilitates the development of scientific literacy by

19 enhancing students' understandings of science content, the processes and logic of

20 scientific inquiry, and the nature of science (Bell et al., 2003). Opportunities to

21 experience science-in-the-making and engaging in discourse with professional scientists

22 could possibly lead to a broader and more complete understanding of the processes and 23 nature of science (Barab \& Hay, 2001; Cohen, 1997; Moss et al., 1998; Ritchie \&

24 Rigano, 1996). Such work projects have the potential to motivate students' interest in 25 learning science (Hughes, 2004), to promote the development of autonomy and self- 
1 motivation to learn (Reid \& Yang, 2002) and, simultaneously, to improve students'

2 thinking and learning capabilities (Duggan \& Gott, 2002; Haigh, 2003).

3

4 Recently, many primary science reform documents advocate the need to develop 5 children's views about scientific activity, through the use of an inquiry-based approach 6 which emphasizes problem solving and critical thinking in a real-world context, as early 7 as possible (e.g. Galvão, 2001; Rocard et al., 2007). Young children are intrinsically 8 interested in science. They are curious about the world around them and about the

9 causes, processes, and mechanisms that underlie biological and physical phenomena 10 (Brown, 1997). However, despite their well-documented natural interest in science, little 11 time is typically allocated to learning science during the early school years (e.g. Weiss, 12 et al., 2003), and so they have few opportunities to learn, not only science concepts, but 13 also the functions and structure of scientific language, discourse, and processes 14 (Mantzicoupolos, Patrick \& Samarapungavan, 2008).

16 Many researchers have shown that participation in real-world activities and events

17 inspires the construction of schemas about the nature of these events (DeMarie, Norman 18 \& Abshier, 2000; Hudson, Shapiro \& Sosa, 1995). There is, however, some debate 19 about what students of different grade levels can do with scientific experiments (Mayer $20 \&$ Carlisle, 1996). Whereas some researchers claim that children often become confused 21 while recording data and making inferences based on those data, unable to construct a 22 coherent scientific explanation (e,g, Kuhn, 1989; Solomon, Duveen \& Hall, 1994), 23 others advocate that children can perfectly understand the task to produce evidence in 24 support of an argument, being able to distinguish between hypotheses and evidence (e.g. 25 Klahr \& Fay, 1993; Sodian, Zaitchik \& Carey, 1991). Although developing a mature 
1 understanding and necessary skills of data collection and interpretation is an essential

2 component of scientific literacy, relatively little attention has been paid to investigating

3 students' conceptions and related skills involved in the collection and interpretation of

4 data (e.g. Gott \& Duggan, 1996; Lehrer \& Schauble, 2002; NRC, 2000; Ryder \& Leach, $52000)$.

6

\section{3. Methods}

8 3.1. Context of the study

9 The outdoor action was performed in a marine biology research laboratory (Guia

10 Marine Laboratory of the Oceanographic Centre of Faculty of Sciences from Lisbon

11 University) and was integrated in a research project funded by the Foundation for

12 Science and Technology: "The role of predation in organising rocky intertidal 13 communities" (PDCT/MAR/58544/2004). The project involved scientific research work

14 and science education actions with children. The scientific component of the project 15 aimed to describe and evaluate predation as a structuring force on intertidal 16 communities, and the purposes of the educational component were to promote scientific

17 literacy through practical science experiments, and to identify children's conceptions 18 about scientists and how they do science.

20 The activity in the laboratory included the following actions: i) a short-guided visit to 21 the laboratory installations; ii) a brief introductory presentation of the project research 22 theme (predation); iii) the development of two experiments about predator and prey 23 interactions, and; iv) students' answers to a questionnaire about the experiments and 24 conceptions.

\subsection{Description of the experiments}


1 The two experiments regarding predator prey interactions were conducted in aquarium

2 tanks at the laboratory. The starfish Marthasterias glacialis (Linnaeus, 1758) was used

3 as a potential rocky shore predator and the prosobranch limpet Patella vulgata L. Was

$4 \quad$ used as prey.

6 The first experiment involved two aquarium tanks. In the first aquarium (procedural

7 control) the starfish and limpets coexisted but were kept apart, whilst in the second

8 aquarium (experimental treatment) the starfish was held next to limpets so that students

9 could see the interactions between the two species. Adult limpets raise their shell, stick

10 out their pallial tentacles, 'mushroom' and 'stomp' on the arms and tube feet of the

11 starfish, often driving them away (Hawkins \& Jones, 1992).

12

13 The second experiment tested if the observed interaction, i.e. the limpet defence strategy

14 in the experiment 1 , was due to chemicals in the water (chemoreception) or to the

15 contact plus chemical cues (contact chemoreception). The experimental design involved

16 a control tank, with a limpet placed in seawater, and an experimental treatment with a

17 limpet placed in a tank with water where a starfish had previously been (Faria et al., in 18 press).

\subsection{Participants}

21 The participants were 136 students from three different elementary private schools, two 22 classes per school. All students were at the $4^{\text {th }}$ grade, with $9(57 \%)$ or $10(43 \%)$ years 23 old. The fourth grade was selected because it corresponds to the last year of the first 24 cycle of basic education (in Portugal) and we wanted to access how children can understand scientific inquiry when they are involved in science research activities, 
1 before entering in a new cycle of education, where they will be engaged in more

2 complex science activities. In Portugal, during this first cycle of education, science

3 issues are studied as a multidisciplinary subject (including history and geography).

4 After this cycle, natural sciences are a distinct curricular subject. The gender balance of

5 students was $55 \%$ males and $45 \%$ females. The work performed in the laboratory was

6 supervised by marine biology researchers. Although the experiments were previously

7 designed and all the material and equipment was assembled by marine researchers, the

8 activity was open to students' participation. Throughout the activity students had the

9 opportunity to make observations, to draw conclusions, to generate new hypotheses, and

10 to design an experiment in order to test those new hypotheses (experiment 2).

11 Additionally, they discussed the characteristics of scientific experiments such as the role

12 of control procedures. By the end of the activity, students reached a certain level of

13 understanding not only about the diversity of anti-predator behaviours, but also about

14 scientific procedures, such as formulating a research problem, stating hypotheses,

15 designing experiments, collecting and recording data, and drawing conclusions based on 16 evidence.

\subsection{Methods of Data Collection}

19 Several methods were used for collecting data, such as, direct and indirect observations

20 and enquiry by questionnaire. During all the activity, whereas one of the researchers

21 oriented the presentation and experiments, the other observed children's behaviour and

22 recorded their questions and oral answers. Additionally, each visit was video recorded 23 in order to design learning materials, such as a hyper video. 
1 Participants answered three questionnaires. The first one was administered before the

2 laboratory activity to 136 students at school in their classrooms, and the other two were

3 applied at the end of the activity, in the laboratory to 100 students.

4

5 The first questionnaire, with the purpose to identify children's previous habits towards

6 science, included questions about their habits of visiting science museums, exhibitions

7 and fairs. Students were also asked about the regular use of the Internet and TV.

8 Finally, they were asked about their interest in science and how often and with whom

9 they do experiments.

10

11 The second questionnaire, with the purpose to identify children's ability to differentiate

12 between the different scientific stages, included open-ended questions related to both

13 experiments. Concerning the first experiment, children were asked about the purpose of

14 the experiment ('what they want to see with the experiment') and to state hypotheses

15 ('what they expected that would happen'). They were also asked about what they

16 observed ('what did they see') while the interaction between the starfish and limpet

17 took place. Finally they were invited to draw a conclusion ("how did they explain what

18 happened in the experiment') and to explain why they used a control aquarium tank in

19 the experiment. In the second experiment, children were also asked about the purpose

20 of the experiment, and invited to state hypotheses, make observations and draw

21 conclusions. Finally children were invited to draw a general conclusion about both

22 experiments ('what conclusion can you reach based on both experiments'). 
1 The third questionnaire, with the purpose to identify children's conceptions about

2 scientists and scientific work, included two open-ended questions, namely 'why do

3 scientists make experiments' and 'what must a scientist think to make an experiment.'

\section{$5 \quad 3.5$. Data analysis}

6 For the analysis of answers to both open-ended questionnaires, content analysis was

7 performed. The answers of the questionnaire related to the differentiation of scientific

8 stages were grouped according to six categories previously defined: i) Purpose of the

9 study; ii) Hypotheses (only for experience 1); iii) Observations; iv) Explanations; v)

10 Control; vi) General conclusions of both experiments. To analyse the conceptions about

11 scientists and scientific work several categories were established for the different types

12 and meanings of students' answers.

14 In order to analyse if there was any influence of students' habits towards science

15 (obtained in questionnaire 1) on children's ability to differentiate between the different scientific stages (results of the second questionnaire) and on children's conceptions

17 about scientists and scientific work (results of the third questionnaire), a Multiple

18 Correspondence Analysis ( $\mathrm{n}=97)$ was performed to define the participants' profile, i.e.

19 their habits of visiting science museums, exhibitions, fairs and of TV and the Internet

20 use. The purpose of this analysis was to characterise the habits of each student in

21 relation to all the different indicators used in the questionnaire (see Table 1). Based on this analysis two dimensions were extracted (Cronbach's alpha coefficient: $\alpha_{1}=0,785$; $\alpha_{2}=0,472$ ) (see Table 2). The participants' scores on each resulting dimension was computed and, based on these scores all participants were subsequently clustered on 
1 were considered (each group includes only those children who performed all of the

2 referred actions):

3 - Group 1: children who regularly go to museums, exhibitions and fairs related to science; they also see documentaries, science programs and use the Internet for school work $(n=33)$;

- Group 2: children who regularly go to museums, exhibitions, and fairs in general, but not to science events; they do not usually see documentaries nor science programs $(n=46)$;

- Group 3: children who usually don't go to museums, exhibitions, and fairs; they

\section{Results}

23 During the oral introductory presentation of the research theme at the laboratory,

24 students were asked about several aspects of predation and they revealed a good

25 previous knowledge on the predator-prey relation, giving a large number of examples. 
1 In addition, the majority of them also revealed that predators weren't always successful

2 in catching their prey, namely because of prey fleeing or prey defence.

3

\section{4.1. Differentiation of scientific stages}

5 The student's answers concerning the differentiation of scientific stages (second 6 questionnaire), organized according to the 6 categories considered, are presented in 7 Table 3:

13 In general, children showed a good comprehension of the purpose of the activities (66

14 or $53 \%$ for experience 1 and experience 2 respectively) (Table 3). They understood the

15 problem that they were dealing with, and gave a well defined objective for each of the 16 experiments, based on the background knowledge given in the introductory 17 presentation.

19 Concerning the second stage, almost all of them (95\%) knew what was going to be

20 tested. For example, in the first experiment, the hypotheses advanced by the children

21 mentioned that predation will occur (e.g. 'The starfish will eat the limpet') or that the

22 limpet will have a defence strategy (e.g. 'The limpet runs away', 'The limpet will protect itself inside the shell') (Table 3). 
1 The major problem revealed by children in the observation category, was the incapacity

2 to distinguish observations from interpretation, giving even anthropomorphic

3 explanations (e.g. 'The starfish wanted to eat the limpet but could not do it'). Children's

4 capacity to describe observations varied also on both experiments. In the first one, only

$529 \%$ described correctly what they had observed, whereas in the second experiment

$660 \%$ of the students gave good descriptions of what they had observed during the

7 activity (Table 3$)$.

8

9 As for the explanation category, the majority of children seemed capable of giving an

10 adequate explanation of what happened in each experiment (60 and 55\% for experiment

111 and 2 respectively). In this case, the main difficulty showed by students was again the

12 confusion between explanations and observations (e.g. 'The limpet clamped down the

13 starfish arm'). A minority of students gave a speculative explanation (7and $6 \%$ for

14 experiment 1 and 2 respectively) (Table 3$).$

16 In what concerns the control category, the majority of students (69 and 58\% for

17 experiment 1 and 2 respectively) seemed to misunderstand the underlying idea of a

18 control aquarium. Most of them were not able to explain the reason of having a second

19 tank in both experiments, with the starfish and limpets kept apart (first experiment) and

20 with only the limpet in seawater (second experiment). However, some students were

21 able to explain the need to evaluate the results by comparing the experimental treatment

22 and the procedural control, and some of them mentioned the control situation as a

23 'natural behaviour', without making a comparison with the experimental treatment (31

24 and $17 \%$ for experiment 1 and 2 respectively) (Table 3). 
1 Finally, children revealed some difficulty in stating general conclusions. Indeed, 59\% of

2 them didn't reach an adequate conclusion after the two experiments, giving only a

3 general and some times a wrong conclusion (e.g. 'There are predators and victims';

4 'The starfish doesn't eat limpets') (Table 3).

6 Another aspect revealed by our direct observations during the development of the

7 experiments was that children, when asked about how the limpet is able to feel the

8 starfish, suggested a variety of possibilities, namely by visual, tactile (direct touch or

9 water vibrations) and chemical ('smell') senses. In addition, when asked about what we

10 could do to understand how the limpet feels the starfish (planning of the experimental

11 design of experiment 2) they also suggested a variety of experimental designs adequate

12 to their hypotheses: putting the starfish and the limpet together in the same tank, but

13 without touching each other, to test if the limpet feels the starfish by direct touch; make

14 vibrations in the water where the limpet was (without the starfish) to test if the limpet

15 feels the starfish by water vibrations. The main difficulty evidenced by children seemed

16 to be how to differentiate and control separately the different variables.

17

18 4.2. Student's conceptions about scientists and scientific work

19 Analysis of the answers to the third questionnaire showed that children's conceptions

20 about scientists and scientific work involved several domains, namely: substantive

21 knowledge, procedural knowledge, motivation and scientists' personality.

22

23 When asked about 'Why do scientists make experiments?' children's answers fell into 3

24 major categories (Figure 1.a): 
1 Knowledge (62\%): 'they want to understand or discover new things'

2 Process (23\%): 'to experiment and see the result...'

3 Motivation (14\%): 'because it is amusing, funny...'

4

5 The answer to the question 'What must a scientist think to make an experiment?'

6 revealed three categories (Figure 1.b):

7

8 Process (67\%): 'The scientist has to think on the materials he is going to use'

9 Knowledge (16\%): 'The scientist has to study and to know things that he is going to

10 experiment...'

11 Scientist personality (13\%): 'The scientist has to be calm, curious,...'

12

13

14

15

16

17 4.3. Students habits towards science and possible implications in science understanding

18 and conceptions

19 The questionnaire about children habits toward science (first questionnaire) revealed

20 that the majority of them regularly go to museums, exhibitions and fairs $(77 \%, 74 \%$ and

$2155 \%$ respectively). History museums (67\%), art exhibitions (69\%) and art fairs (53\%)

22 were the most visited. Concerning science events, 53\% of the children visited science

23 exhibitions, 33\% science museums and $29 \%$ science fairs. In addition, almost all

24 children answered that they use the Internet (98\%), particularly for school research 
1 (62\%). Finally, science programs watched by them on TV were mainly documentaries

$2(46 \%)$ and science experiments $(41 \%)$.

3

4 Almost all children showed that they like sciences (96\%). The reasons they mentioned 5 for this preference were because: it is amusing (65\%); it allows learning new things $6(53 \%)$; it is interesting (24\%). Some of them also referred to curiosity about science $7 \quad(7 \%)$ and that science is useful for their daily life (1\%). Concerning how often and with

8 whom they do experiments all of them were familiar with science experiments because

9 of the weekly science experimental activity in school they mentioned. In addition, they

10 indicate that they also do experiments at home (59\%). They do experiments based on 11 teacher indication (90\%), but they also do them based on the Internet (62\%), books 12 (48\%), TV (43\%), relatives' suggestions (38\%) and friends' suggestions (36\%).

14 The three groups considered concerning children's habits towards science (results of the 15 Correspondence analysis), i.e. children very familiar with cultural and science events 16 (group 1); children familiar with cultural events in general but unfamiliar with science 17 events in particular (group 3); and children unfamiliar with cultural and science events 18 (group 2), revealed no statistical significant differences in the understanding of the 19 activities performed, nor abilities to differentiate between the different scientific stages 20 while they were engaged in scientific investigations (answers to the second 21 questionnaire) (Kruskal-Wallis analysis: $\chi^{2}=1.10, \mathrm{dl}=2, \mathrm{p}>0.05$ ).

23 Children's responses also didn't reveal any statistical significant differences concerning 24 their conceptions about scientists and scientific work (answers to the third 25 questionnaire), independently of their previous familiarity towards science (Kruskal- 
1 Wallis analysis: $\chi^{2}=1.70, \mathrm{dl}=2, \mathrm{p}>0.05$ for the first question; $\chi^{2}=0.06, \mathrm{dl}=2, \mathrm{p}>0.05$ for

2 the second question).

3

4 5. Discussion

5 These results revealed that young children are perfectly able to engage in scientific

6 activities involving prediction, observation, and explanation. Most of the students were

7 able to state hypotheses, make observations, and interpretations of the conducted

8 experiments. However, some students misinterpreted results and conclusions of the

9 experiments, i.e., when asked about observations they gave an explanation and when

10 asked to explain the experiment they described what happened. These results indicated

11 that students have more difficulties in distinguishing between the description of an

12 event, and looking for the causal mechanisms that would enable them to give an

13 explanation. These findings corroborate the work of Solomon et al. (1994).

15 According to Bell et al. (2003) it is generally assumed that students will learn not only

16 how to do science, but also learn essential aspects of science, by doing science, as if

17 implicit instruction on these topics would in fact lead to desired educational outcomes.

18 However, some researchers have suggested that desired understandings may only be

19 achieved through a combination of implicit and explicit messages, with the "expert-

20 apprentice" relationship serving as an effective source of these messages (e.g. Bell et 21 al., 2003; Ryder \& Leach, 1999).

23 Thus, real scientific experiments may be necessary but not sufficient to elicit changes in

24 students' conceptions about science and scientific inquiry. It is important to encourage

25 students to connect the scientific activities they are developing, in the classroom with 
1 the actual scientific enterprise, if we want them to develop understandings of the

2 abstract and complex nature of science and scientific inquiry (Bell et al., 2003). The

3 connection to research laboratories plays a major role here.

4

5 Several studies have already analysed the impact of the participation of precollege (e.g.

6 Barab \& Hay, 2001; Charney et al., 2007; Etkina, Matilsky, \& Lawrence, 2003; Ritchie

7 \& Rigano, 1996) and undergraduate (e.g. Hunter, Laursen, \& Seymour, 2007; Kardash,

8 2000; Lopatto, 2004; Rauckhorst, Czaja, \& Baxter Magolda, 2001) students in

9 laboratory or field research activities supervised by scientists. Most of these studies

10 have highlighted the real nature of the experiments as a crucial aspect for the

11 development of a deep understanding about scientific activity and science processes.

13 According to Feldman et al. (2009), whereas traditional apprenticeships, which only

14 requires peripheral participation from students only develops expert practitioners, cognitive apprenticeships, where students are really engaged in authentic activities

crucial factor to promote the development of students' desirable scientific practices, despite the fact that the planning and the set-up were made by the supervisor rather than by students.

The present study was conducted within a marine research institution context where expert scientists provided students' supervision. This study differed in several aspects 
1 education (9 or 10 years old). Despite the acknowledged necessity of science education

2 in early ears, this is often overlooked in real context studies. Secondly, in this study the

3 activity was open to students' participation. Although there was a previous framework

4 done by the scientists (e.g. material and equipment), the students had the opportunity to

5 participate in every stage of the experimental activity. Additionally, they were

6 encouraged to reflect and discuss about all stages of the experiments, trying to make

7 students aware about the different scientific processes involved. Some authors (e.g.

8 Roth, 1994) consider that this type of open-ended laboratory sessions is best for all

9 students. Thirdly, our study had a great number of participants in the inquiry-based

10 activity. According to Ritchie and Rigano (1996) caution needs to be taken before

11 advocating open-ended inquiry for all. The investigation of McRobbie and Fraser (1993,

12 in Ritchie \& Rigano, 1996) has demonstrated that, while it was possible for students in

13 classes with a structured environment to have positive attitudes toward science, it was

14 also possible for students in open-ended classrooms to have negative attitudes toward

15 science. Working with a larger sample of students in the present study enabled us to

16 detect their major difficulties while engaged in scientific experimental work. Finally,

17 this activity was designed so that it could be implemented both in marine research

18 institutes and in school classrooms. Several authors (e.g. Bereiter, 1994; Ritchie \&

19 Rigano, 1996) have addressed the question of the effectiveness of apprenticeship

20 models in schools, giving many teachers' difficulties in guiding students' scientific

21 experiments. As we are aware of this limitation, the present study, apart from bringing

22 students to science, promoting the collaboration between schools and research

23 laboratories, proposes one activity that can effectively be implemented in the school

24 context. In fact, these experiments have been proposed previously as a hands-on activity

25 that any science teacher can develop in any science classroom (Faria et al., in press). 
2 One implication of the present study is that, despite the great importance of this type of

3 outdoor action for children's education to promote effective learning, more care should

4 be taken so that children can overcome difficulties. Clearly, this type of activities has

5 the potential for students to receive both implicit and explicit messages about scientific

6 inquiry. However, as suggested by Bell et al. (2003) science educators must have an

7 important role in this respect, either in providing orientation for scientists that

8 collaborate in these research experiences, or to alert them to the common nature of

9 children's scientific inquiry misconceptions and to the importance of explicit instruction

10 in overcoming these misconceptions.

12 A possible way to overcome these difficulties would be to develop a follow-up learning 13 activity in the classroom, if possible with both the science educator and the scientist, to

14 promote and consolidate these learning outcomes. In what concerns the differentiation 15 of scientific stages, teachers could overcome difficulties by assigning to several groups 16 of students a different task or scientific stage of the experiment. At the end of the 17 experiment, all stages should be completed getting the results of each group. The cooperation of the class and the discussion of results obtained by each group could help

19 children to improve and overcome difficulties. In another activity the teacher would 20 change the group task.

22 According to Hodson (1992) the promotion of a large variety of opportunities to 23 perform investigations in a different range of scientific contexts probably will 24 encourage students to develop the sort of tacit, intuitive knowledge in their science 25 investigative abilities that results from experience and understanding. As already stated 
1 by some authors (e.g. Peterson \& French, 2008; Tytler \& Peterson, 2003), in this work

2 it was clear that these opportunities could, and probably should, begin from the earliest

3 age, taking advantage of children's curiosity and willingness to understand the natural

4 world around them. As suggested by Tytler and Peterson (2003), first grade teachers

5 need to listen to children's questions and ideas, and must learn how to challenge and

6 support these with recourse to evidence. This needs to be done through a combination of

7 active investigation, pursuing significant ideas and undertaking interesting and

8 productive explorations that involve coordinating ideas and evidence, and scientific

9 reasoning and argumentation.

11 Another outcome of the present work was that students' conceptions about scientists

12 and scientific work revealed that substantive knowledge seems to be more important

13 when children are asked about 'Why do scientists make experiments?' and procedural

14 knowledge seems to be more important when children are asked about 'What must a

15 scientist think when he is going to make an experiment?'. It is possible that the

16 students' conceptions mirror the opportunity they had in this study to explore and reflect

17 about the need of both substantive and procedural knowledge in doing science. Indeed,

18 to completely understand and perform this activity students had to get some previous

19 knowledge about the marine organisms involved namely their habitat and feeding

20 relations. Additionally, having to discuss all experimental procedurals involved and

21 planning how to test their own hypothesis, they also had to reflect about scientific

22 procedural aspects.

24 Finally, this study showed no relation between students with different attitudes toward

25 science, (i.e. students very familiar with cultural and science events, students unfamiliar 
1 with cultural and science events, and students familiar with cultural events in general

2 but unfamiliar with science events in particular) and the understanding about scientific

3 experiments, the different ability to differentiate between scientific stages, or

4 conceptions about the scientists and scientific work. The fact that child's prior attitudes

5 did not seem to affect their abilities to differentiate between science stages, nor scientist

6 work, is an interesting outcome of the present study. It is possible that the high social

7 level of the students and the fact that the schools were in an urban area accounted for

8 this result. This issue should be further investigated in the future to provide further

9 insights into how to promote the best scientific literacy in young children.

11 References

12 Anderson, R.D. (2007). Inquiry as an organizing theme for science curricula. In: Abell 13 SK, Lederman NG (eds) Handbook of research on science education. Lawrence 14 Erlbaum Associates Publishers, New Jersey, pp 807-830.

15 Atkin, J.M. \& Black, P. (2003). Inside science education reform: A history of curricular and policy change. New York, Teachers College Press.

Barab, S.A. \& Hay, K.E. (2001). Doing science at the elbows of experts: Issues related to the science apprenticeship camp. Journal of Research in Science Teaching, 38,

Bell, R.L., Blair, L.M., Crawford, B.A. \& Lederman, N.G. (2003). Just Do It? Impact of a Science Apprenticeship Program on High School Students' Understandings of the Nature of Science and Scientific Inquiry. Journal of Research In Science Teaching, 40(5), 487-509.

24 Bereiter, C. (1994). Constructivism, socioculturalism, and Popper's World 3. Educational Researcher, 23( 2), 1 -23. 
1 Bleicher, R.E. (1996). High school students learning science in university research 2 laboratories. Journal of Research in Science Teaching, 33, 1115-1133.

3 Brown, A. (1997). Transforming schools into communities of thinking and learning 4 about serious matters. American Psychologist, 52, 399-413.

5 Charney, J., Hmelo-Silver, C.E., Sofer,W., Neigborn, L., Coletta, S., \& Nemeroff, M. 6 (2007). Cognitive apprenticeship in science through immersion in laboratory practices. International Journal of Science Education, 29(2), 195-213.

8 Chin, C. \& Kayalvizhi, G. (2002). Posing problems for open investigations: What questions do students askquest; Research in Science \& Technological Education,

11 Cohen, K. C. (1997). Internet Links for Science Education: Student- Scientist 12 Partnerships, New York, Plenum Press.

13 DeMarie, D., Norman, A. \& Abshier, D. W. (2000). Age and experience influence 14 different verbal and nonverbal measures of children's scripts for the zoo. Cognitive Development, 15, 241-262.

16 Duggan, S. \& Gott, R. (2002). What sort of science education do we really needquest. International Journal of Science Education, 24(7), 661-680.

18 Etkina, E., Matilsky, T., \& Lawrence, M. (2003). Pushing to the edge: Rutgers astrophysics institute motivates talented high school students. Journal of Research in Science Teaching, 40(10), 958-985.

21 Faria, C., Boaventura, D., Galvão, C \& Chagas, I (in press). Do predators always win? 22 Starfish versus limpets: a hands-on activity examining predator-prey interactions School Science Review. 
1 Feldman, A., Divoll, K, \& Rogan-Klyve, A (2009). Research Education of New Scientists: Implications for Science Teacher Education. Journal of Research in Science Teaching, 46(4), 442-459.

Hawkins, S.J. \& Jones, H.D. (1992). Rocky shores. Marine field course guide 1. London, Immel Publishing.

Hipkins, R., Bolstad, R., Baker, R., Jones, A., Barker, M., Bell, B., Coll, R., Cooper, B., Forret, M., Harlow, A, Taylor, I., France, B. \& Haigh, M. (2001). Curriculum, learning and effective pedagogy: A literature review in science education. Wellington, New Zealand, Ministry of Education.

Hodson, D. (1992). Assessment of practical work: Some considerations in philosophy of science. Science \& Education, 1, 115-144.

Hofstein, A. \& Lunetta, V. (2003). The laboratory in science education: Foundations for the twenty-first century. Science Education, 88(1), 28-54. 
1 Hudson, J. A., Shapiro, L. R. \& Sosa, B. B. (1995). Planning in the real world:

2 Preschool children's scripts and plans for familiar events. Child Development, 66:

$3984-998$.

4 Hughes, P. (2004). Mainstream chemical research in school science. School Science 5 Review, 85(312), 71-76.

6 Hume, A. \& Coll, R. (2008). Student experiences of carrying out a practical science 7 investigation under direction. International Journal of Science Education, 30(9), 1201-1228.

9 Hunter, A.-B., Laursen, S.L., \& Seymour, E. (2007). Becoming a scientist: The role of 10 undergraduate research in students' cognitive, personal, and professional 11 development. Science Education, 91(1), 36-74.

12 Kardash, C. (2000). Evaluation of an undergraduate research experience: Perceptions of 13 undergraduate interns and their faculty mentors. Journal of Educational 14 Psychology, 92(1), 191-201.

15 Klahr, D. \& Fay, A. L. (1993). Heuristics for scientific experimentation: a 16 developmental study. Cognitive Psychology, 25, 111-146.

17 Kuhn, D. (1989). Children and adults as intuitive scientists. Psychological Review, 96, 18 674-689.

19 Lederman, N.G. (1992). Students' and teachers' conceptions of the nature of science: A 20 review of the research. Journal of Research in Science Teaching, 29, 331-359.

21 Lehrer, R. \& Schauble, L. (Eds.) (2002). Investigating real data in the classroom. New 22 York, Teachers College.

23 Lopatto, D. (2004). Survey of undergraduate research experiences (SURE): First 24 findings. Cell Biology Education, 3, 270-277. 
1 Mant, J., Wilson, H. \& Coates, D. (2007). The effect of increasing conceptual challenge in primary science lessons on pupils' achievement and engagement. International Journal of Science Education, 29(14), 1707-1719.

Mantzicopoulos, P.; Patrick, H. \& Samarapungavan, A. (2008). Young children's motivational beliefs about learning science, Early Childhood Research Quarterly, $23,378-394$

Matthews, M.R. (1994). Science teaching: The role of history and philosophy of science. New York, Routledge.

Mayer, K. \& Carlisle, R. 1996. Children as experimenters. International Journal of Science Education, 18(2), 231-248.

Meichtry,Y.J. (1992). Influencing student understanding of the nature of science: Data from a case of curriculum development. Journal of Research in Science Teaching, 29, 389-407.

Millar, R. \& Osborne, J. (Eds) (1998). Beyond 2000: Science Education for the Future. The report of a seminar series funded by the Nuffield Foundation; http://www.kcl.ac.uk/education.

Moss, D.M.; Abrams, E.D. \& Kull, J.A. (1998). Can we be scientists too? Secondary students' Perceptions of scientific research from a Project-based classroom. Journal of Science Education and Technology, 7(2), 149-161.

Nakhlel, M.B., Polles, J. \& Malina, E. (2002). Learning chemistry in a laboratory environment. In J. Gilbert, O. De Jong, R. Justi, D.F. Treagust \& J. H. Van Driel (Eds.), Chemical research: Towards research-based practice (pp. 69-94). Dordrecht, Netherlands: Kluwer. 
1 National Research Council. (2000). Inquiry and the national science education standards: A guide for teaching and learning.Washington, DC, National Academy

3 Press.

4 Peterson, S.M. \& French, L. (2008). Supporting young children's explanations through inquiry science in preschool. Early Childhood Research Quarterly, 23, 395-408.

6 Rauckhorst, W.H., Czaja, J.A., \& Baxter Magolda, M. (2001). Measuring the impact of the undergraduate research experience on student intellectual development. Paper

9 Reid, N. \& Yang, M-J. (2002). Open-ended problem solving in school chemistry: A preliminary investigation. International Journal of Science Education, 24(12),

12 Ritchie, S.M.\& Rigano, D.L. (1996). Laboratory apprenticeship through a student research project. Journal of Research in Science Teaching, 33, 799-815.

14 Richmond, G. \& Kurth, L.A. (1999). Moving from outside to inside: High school students' use of apprenticeships as vehicles for entering the culture and practice of science. Journal of Research in Science Teaching, 36, 677-697.

Rocard, M., Csermely, P., Jorde, D., Lenzen, D., Walberg-Henriksson, H. \& Hemmo, V. (2007). Science Education now: a renewed pedagogy for the future of Europe.

Roth, W. -M. ( 1994). Experimenting in a constructivist high school physics laboratory. 24 Journal of Research in Science Teaching, 31, 197-223. 
1 Ryder, J. (2001). Identifying science understanding for functional scientific literacy. Studies in Science Education, 36, 1-44.

3 Ryder, J. \& Leach, J. (1999). University students' experiences of investigative project work and their images of science. International Journal of Science Education, 21, 945-956.

6 Ryder, J. \& Leach, J. (2000). Interpreting experimental data: the views of upper secondary school and university science students. International Journal of Science Education, 22(10), 1069-1084.

Schreiner, C. \& Sjøberg, S. (2004). Rose. The relevance of science education. Department of Teacher Education and School Development, University of Oslo.

Singer, S.R.; Hilton, M.L. \& Schwiengruber, H.A. (Eds) (2005). America's lab report: investigations in school science. Washington, DC, National Academy Press.

Sodian, B., Zaitchik, D \& Carey, S. (1991). Young children's, differentiation of hypothetical beliefs from evidence. Child Development, 62, 753-766.

Solomon, J.; Duveen, J. \& Hall, S. (1994). What's happened to biology investigations? Journal of Biological Education, 28(4), 261-266.

Tytler, R. \& Peterson, S. (2003). Tracing Young Children's Scientific Reasoning. Research in Science Education 33, 433-465, 2003.

Weiss, I. R., Pasley, J. D., Smith, P. S., Banilower, E. R. \& Heck, D. J. (2003). A study of k-12 mathematics and science education in the United States. Chapel Hill, NC: Horizon Research. Retrieved from http://www.horizon-research.com/ insidetheclassroom/reports/looking/.

Zohar, A. (1998). Result or conclusion? Students' differentiation between experimental results and conclusions. Journal of Biological Education, 32(1); 53-59. 


\section{Acknowledgements}

This research was supported by a research project 'The role of predation in organizing rocky intertidal communities’ (PDCT/MAR/58544/2004) funded by the Portuguese Foundation for Science and Technology (FCT). The authors thank Sónia Brazão and Ana Pêgo for their support in the laboratory experiences and field sampling. We also would like to express our gratitude to the teachers and children involved in this study. 
1

Table 1. Attitudes toward science indicators.

\begin{tabular}{|c|c|c|c|}
\hline Indicator & & $n$ & no answer \\
\hline \multirow[t]{2}{*}{ Museums } & Yes & 75 & \\
\hline & No & 22 & 0 \\
\hline \multirow[t]{2}{*}{ Science museums } & Yes & 24 & \\
\hline & No & 51 & 22 \\
\hline \multirow[t]{2}{*}{ Exhibitions } & Yes & 75 & \\
\hline & No & 22 & 0 \\
\hline \multirow[t]{2}{*}{ Science exhibitions } & Yes & 41 & \\
\hline & No & 34 & 22 \\
\hline \multirow[t]{2}{*}{ Fairs } & Yes & 52 & \\
\hline & No & 45 & 0 \\
\hline \multirow[t]{2}{*}{ Science fairs } & Yes & 22 & \\
\hline & No & 30 & 45 \\
\hline \multirow[t]{2}{*}{ Use of Internet for school } & Yes & 57 & \\
\hline & No & 39 & 1 \\
\hline \multirow[t]{2}{*}{ Use of science books } & Yes & 30 & \\
\hline & No & 66 & 1 \\
\hline \multirow[t]{2}{*}{ Use of TV to see science programs } & Yes & 49 & \\
\hline & No & 48 & 1 \\
\hline \multirow[t]{2}{*}{ Use of TV to see science experiences } & Yes & 45 & \\
\hline & No & 52 & 1 \\
\hline
\end{tabular}

$$
\mid
$$

(10


Table 2. Discrimination measures (Multiple Correspondence Analysis)

\begin{tabular}{|lcc}
\hline & \multicolumn{2}{c}{ Dimensions } \\
\hline Museums & 1 & 2 \\
Science museums & $\underline{0.67}$ & $\underline{0.21}$ \\
Exhibitions & $\underline{0.14}$ & $\underline{0.41}$ \\
Science exhibitions & $\underline{0.64}$ & $\underline{0.31}$ \\
Fairs & $\underline{0.14}$ & $\underline{0.44}$ \\
Science fairs & $\underline{0.42}$ & $\underline{0.04}$ \\
Use of Internet for school & $\underline{0.17}$ & $\underline{0.04}$ \\
Use of science books & $\underline{0.19}$ & $\underline{0.01}$ \\
Use of TV to see science programs & $\underline{0.34}$ & $\underline{0.06}$ \\
Use of TV to see science experiences & $\underline{0.38}$ & $\underline{0.13}$ \\
$\underline{\text { Inertia }}$ & $\underline{0.32}$ & $\underline{0.08}$ \\
\hline
\end{tabular}


Table 3 - Differentiation of scientific stages by students of the first cycle of basic education $(\mathrm{n}=1 \overline{0} \overline{0})$.

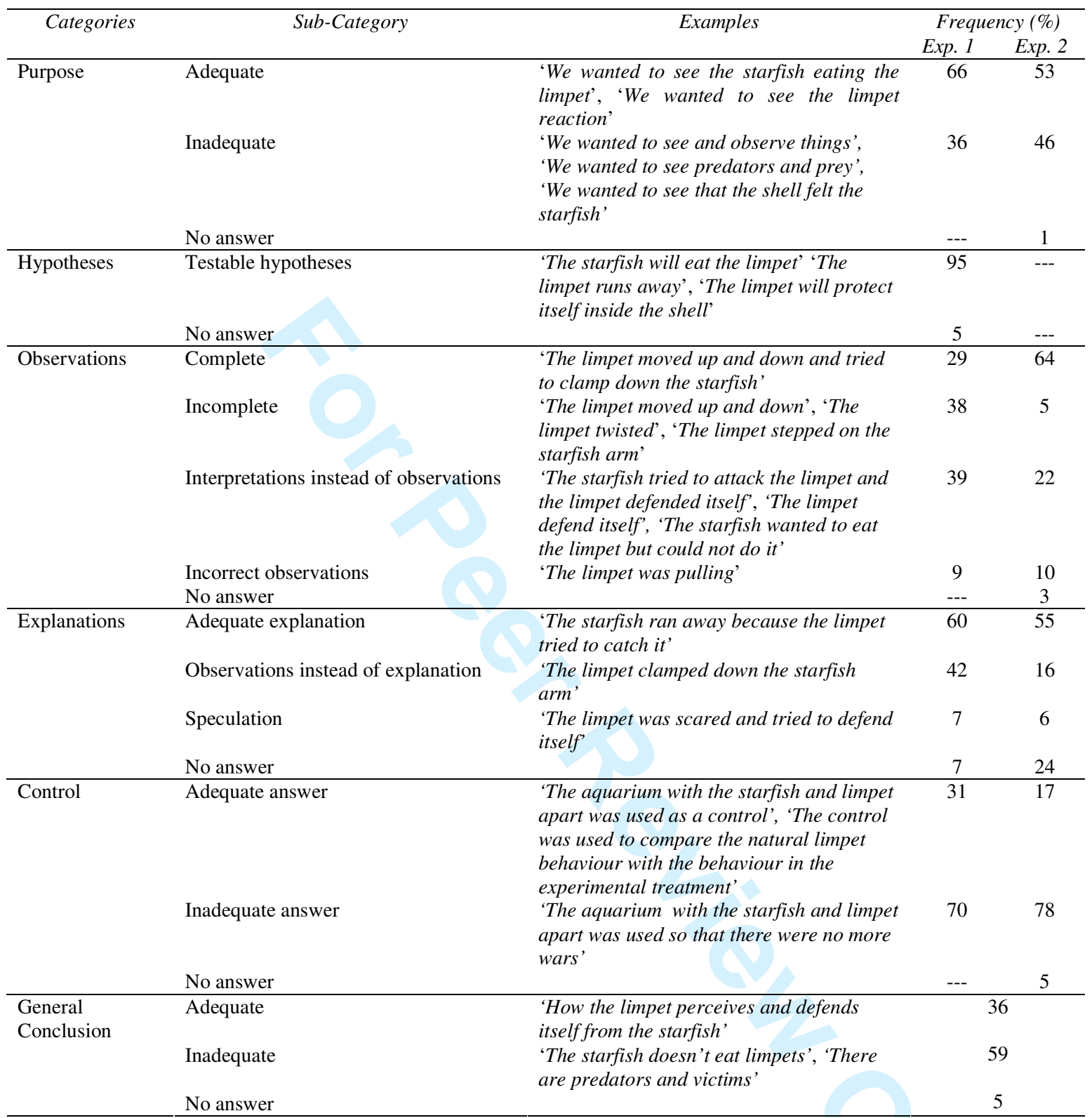


Figure 1.a. Percentage of answers to the questionnaire item 'Why do scientists make experiments?' in the four categories (knowledge, process, motivation, no answer).
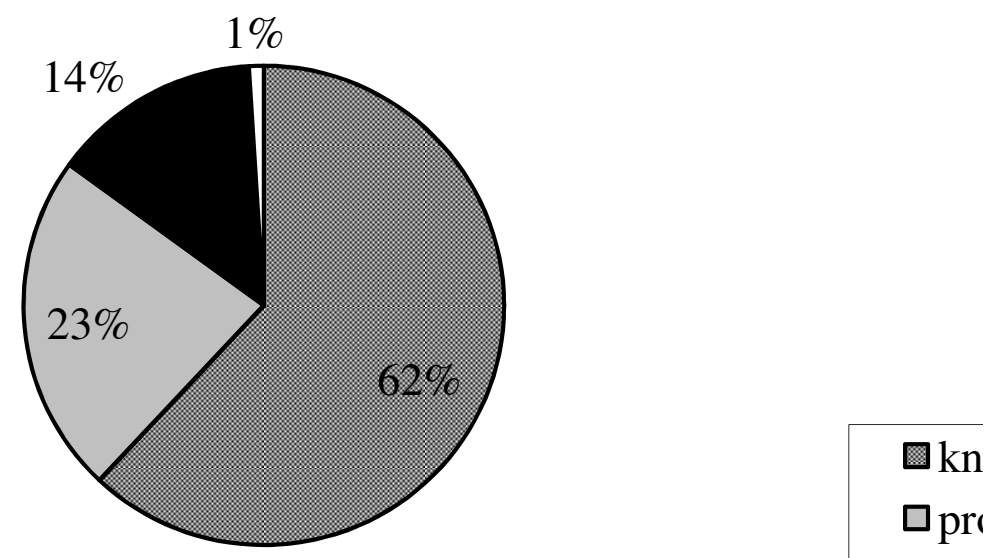

Figure 1.b. Percentage of answers to the questionnaire item 'What must a scientist think when he is going to make an experiment?' in the four categories (knowledge, process, scientist personality, no answer).

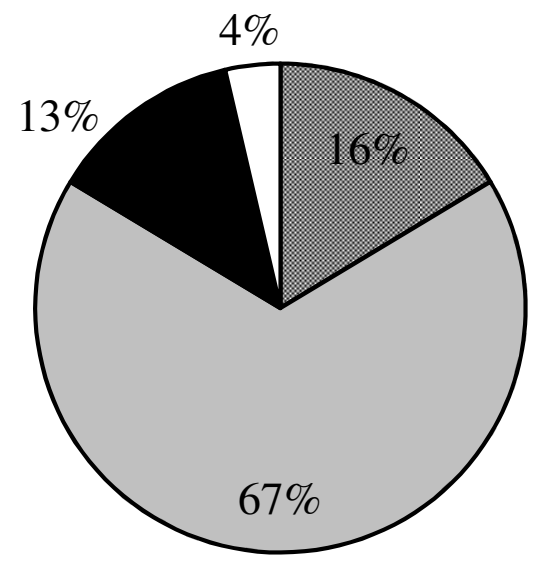

- knowledge

$\square$ process 